\title{
A study of the effect of swirling airflow on fuel spray characteristics under low pressure atmosphere
}

\author{
Kenichi SHIMIZU*1, Takehiko SEO ${ }^{1}$, Masato MIKAMI ${ }^{1}$ \\ ${ }^{1}$ Graduate School of Sciences and Technology for Innovation, \\ Yamaguchi University, Ube, Japan \\ *Corresponding author e-mail : a022vdu@yamaguchi-u.ac.jp
}

\begin{abstract}
Improving engine restart performance at high altitudes is essential to protect the safety of aircraft. This study investigated the fuel spray characteristics in a low-pressure atmosphere field with swirling air flow, focusing on high-altitude reignition of aircraft engines. Silicone oil, which has similar physical properties to jet fuel, was used as the simulated fuel. In addition, a swirl was used to apply a swirling air flow to the spray. The experiment was conducted in a pressure vessel with an internal pressure of $0.025 \mathrm{MPa}$ to simulate the atmospheric pressure at high altitude. The droplet size distribution of the spray was measured using PDPA, and the liquid film breakup process and the behavior of the droplets were obtained by the short-backlit method with a high-speed camera and a pulsed diode laser light source. By increasing the swirling air flow rate, the droplet size distribution of the spray decreased the number of small droplets with a diameter of $30 \mu \mathrm{m}$ or less, and the number of droplets increased toward the circumference. Regarding the liquid film behavior, it was found that the liquid film shape changed to a spindle type as the swirling air flow rate increased.
\end{abstract}

Keywords: Spray characteristics, Swirling air flow, Breakup process,

Low pressure atmosphere

\section{INTRODUCTION}

Global aircraft demand continues to grow, and air passenger transport is expected to more than double over the next 20 years $^{(1)}$. Aircraft engines are being actively developed in response to such aircraft demand, and this development includes low fuel consumption, improvement of thermal efficiency and propulsion efficiency, and noise reduction. Among them, improving high-altitude reignition performance is extremely important for protecting the safety of aircraft. Originally, ignition is performed in a high pressure atmosphere, but if the engine stops while flying over $30,000 \mathrm{ft}$, the pressure in the combustion chamber will be in a low pressure atmosphere equivalent to $0.025 \mathrm{MPa}$ of the outside air, and reignition is expected to be difficult due to unusual fuel spray characteristics. Since optimum premixture formation is required for reliable ignition, it is important to elucidate the spray structure in the previous stage and the atomization mechanism in a low-pressure atmosphere that leads to it. Neya and Sato ${ }^{(2)}$ investigated the effect of ambient air pressure on spray characteristics, and reported that the droplet diameter becomes large and the cause is the liquid film thickness when the ambient air pressure is lower than atmospheric pressure. Fraser ${ }^{(3)}$ also studied under the same experimental conditions as described above, and reported that the liquid film splitting morphology changes and the droplet diameter increases under a low-pressure atmosphere. According to Choi et al. ${ }^{(4)}$ who investigated the spray characteristics of actual fuel and water, kerosene was $20 \mu \mathrm{m}$ smaller in droplet diameter than water. Lefebvre ${ }^{(5)}$ investigated the spray characteristics associated with changes in the kinematic viscosity of the liquid and reported that the droplet diameter decreases when the kinematic viscosity 
decreases at the outer edge of the spray. This indicates that the spray shape and the generated droplets differ due to the difference in the physical property values of the liquid even under the same conditions.

Therefore, in this study, silicone oil with a similar surface tension value was used as the jet fuel simulated liquid in a low-pressure atmosphere, and the temperature of the silicone oil was changed to control the kinematic viscosity before spraying. This study investigated the fuel spray characteristics by supplying a swirling air flow to the spray liquid to create an environment that simulates the actual machine.

\section{EXPERIMENTAL APPARATUS AND METHOD}

\subsection{Experimental apparatus}

Figure 1 shows a schematic of the experimental apparatus. A stainless steel pressureresistant container (SUS304, diameter $216.3 \mathrm{~mm}$, height $400 \mathrm{~mm}$ ) was used as the space for spraying the test liquid. To supply the test liquid, the container containing the test liquid is filled with nitrogen gas adjusted by a regulator (YUTAKA, FRILS-OP) and a pressure gauge (Daito Keiki Seisakusyo Co., Ltd., TYPE-AT) and pressurized. The injection pressure $P_{\text {inj, was }}$ constant at 1.0 MPa. A single-hole spiral injection valve (Delavan, TYPE WDA angle $60^{\circ}$ nozzle number 2.0) and a swirler (outer diameter $70 \mathrm{~mm}$, inner diameter $36 \mathrm{~mm}$, blade angle $45^{\circ}$, number of blades 16 , blade thickness $1 \mathrm{~mm}$, swirl number 0.78 ) were attached inside the pressure-resistant container in which the spray is formed. The swirling direction of the liquid and the swirling air direction by the swirler are opposite. The swirling air flow was supplied by opening valve 1 while the vacuum pump (SHINKO SEIKI Co., Ltd., SW-50S) shown in Fig. 1 was operating. The measurement of the swirling air flow rate at that time was adjusted while checking with the flow sensor for the amplifier-separated aircraft (KEYENCE Co., Ltd., FD-A600) and the amplifier unit (KEYENCE Co., Ltd., FD-V40A). The pressure chamber was depressurized by a vacuum pump (SHINKO SEIKI Co., Ltd., SW-50S). The pressure of the inside of the chamber, ambient pressure $P_{a m b}$, was measured using a vacuum gauge (OMRON Co., Ltd., E8F2-ANOC) which was connected to the pressure chamber by a stainless steel tube. In this study, $\mathrm{P}_{\text {amb }}$ was $0.025 \mathrm{MPa} \cdot a b s$, and the swirling air flow was supplied at $400 \mathrm{~L} / \mathrm{min}$ in that state.

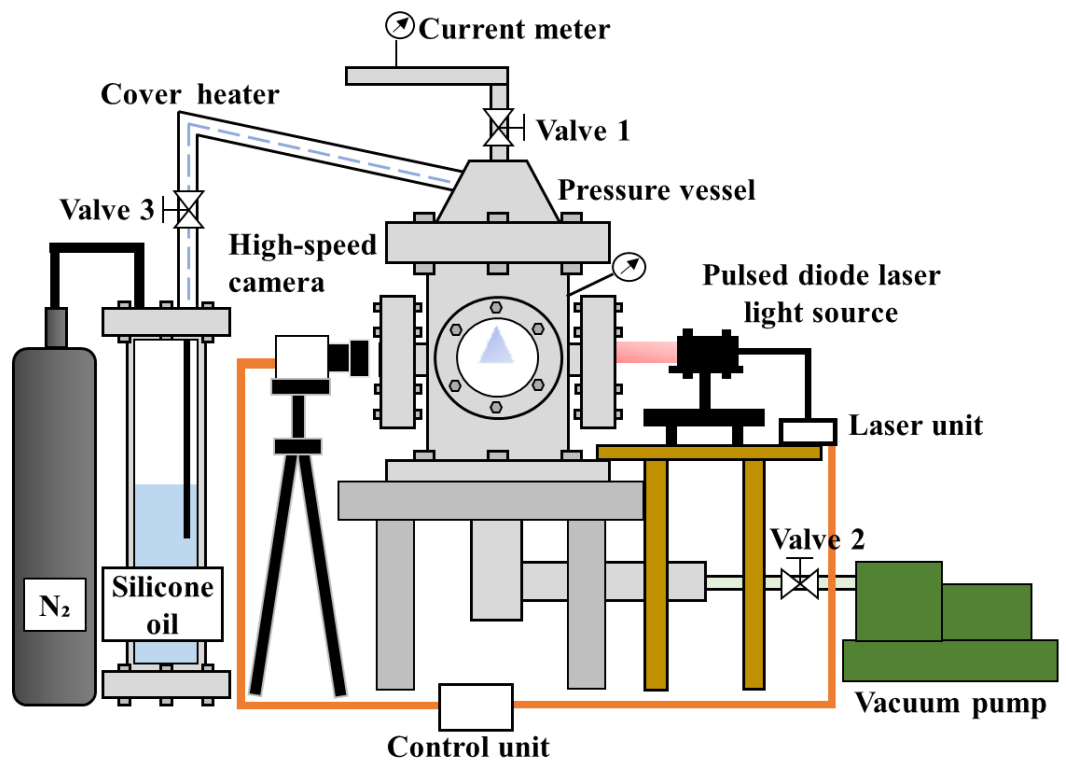

Fig.1 Experimental apparatus 
Table 1 Difference in physical characteristics between jet fuel and silicone oil

\begin{tabular}{|c|c|c|c|}
\hline & $\begin{array}{c}\text { Surface tension } \\
{[\mathrm{mN} / \mathbf{m}]}\end{array}$ & $\begin{array}{c}\text { Kinematic viscosity } \\
{\left[\mathbf{m m}^{2} / \mathbf{s}\right]}\end{array}$ & $\begin{array}{c}\text { Density } \\
{\left[\mathbf{g} / \mathbf{c m}^{3}\right]}\end{array}$ \\
\hline JET-A [265K] & 25 & 8.5 & 0.7753 \\
\hline Silicone oil [298K] & 24.4 & 15 & 0.9932 \\
\hline
\end{tabular}

\subsection{Jet fuel simulated liquid}

In this experiment, it is necessary to use a liquid close to the physical properties of jet fuel in order to simulate the test liquid as jet fuel (JET-A). Therefore, silicone oil (Shin-Etsu Chemical Co., Ltd., KF-56A), whose surface tension value is close to that of jet fuel and whose kinematic viscosity can be easily controlled, was used as the test liquid. Table 1 shows the difference in each physical property value. $\mathrm{Kanda}^{(6)}$ investigated the dependence of surface tension and kinematic viscosity with temperature changes of silicone oil, and reported that the surface tension value was almost the same between the temperatures of $298 \mathrm{~K}$ and $313 \mathrm{~K}$, but the kinematic viscosity value changed from $13.8 \mathrm{~mm}^{2} / \mathrm{s}$ to $8.5 \mathrm{~mm}^{2} / \mathrm{s}$, which is equivalent to jet fuel. Based on this result, in this study, the tube cover heater (Tokyo Institute of Technology, SRX-6.35-05) was used to heat the supply pipe immediately before the pressureresistant container to heat the silicone oil flowing inside the pipe, to lower the kinematic viscosity value.

\subsection{Experimental method and conditions}

The spray shape was visualized by the short-backlit method. The pulsed diode laser light source(Cavitar Ltd., CAVILAX smart laser unit) is dimmed with a light amount reduction filter (Kenko Tokina Co., Ltd., MC Filter, ND400) and irradiated to the spray as a backlight, and the transmitted light is emitted by a high-speed camera (Vision Research Inc., Phantom VEO 710). These synchronizations were performed by directly inputting the trigger signal output from the high-speed camera to the control unit of the pulsed diode laser light source (Cavitar Ltd., CAVILAX control unit). The frame rate for shooting was set to $7,500 \mathrm{fps}$.

A Phase Doppler Particle Analyzer (PDPA)(TSI / Aerometrics, 2D-PDPA) shown was used to measure the diameter of the sprayed droplets. In this experiment, an Ar ion laser with a wavelength of $514 \mathrm{~nm}$ was used to measure the point downstream from the hole at $Z=35$ $\mathrm{mm}$ and the radial direction from the hole at $X=0$ to $15 \mathrm{~mm}$ at $3 \mathrm{~mm}$ intervals. The measurement points are shown in red plots in the image in Fig. 2. By installing the transmitter and receiver on an L-shaped rail attached to a traverse device (Chuo Seiki Co., Ltd., ADSL$230-\mathrm{C} 2 \mathrm{P}$ ). Their focal length is $500 \mathrm{~mm}$. The beam intersection angle is $5^{\circ}$. PDPA measurement was completed when 10000 droplets were measured or when 60 seconds passed at each measurement point.

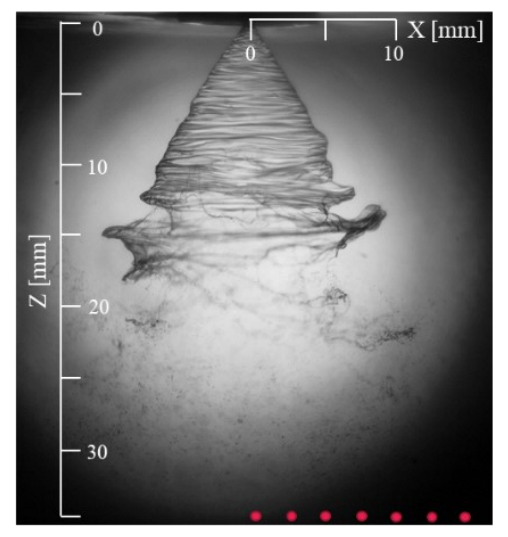

Fig.2 PDPA measurement points 


\section{RESULTS AND DISCUSSIONS}

\subsection{Effect of kinematic viscosity on spray shape}

Figure 3 shows the difference in spray shape and liquid film length between $298 \mathrm{~K}$ and $313 \mathrm{~K}$ silicone oil under a low pressure atmosphere $\left(\mathrm{P}_{\mathrm{amb}}=0.025 \mathrm{MPa} \cdot \mathrm{abs}\right)$. The average value of the liquid film length shown in the red plot in the figure was obtained from 10 consecutive spray images. Since there is a significant difference in the liquid film length between the two kinematic viscosities, the kinematic viscosity value will have a large effect on the liquid film length. In a viscous fluid, the kinematic viscosity value affects the shear force between gas and liquid, and the higher kinematic viscosity takes a long time to break up, so the liquid film will be longer. In addition, in the spray shape of $v=8.5 \mathrm{~mm}^{2} / \mathrm{s}$, a spiral wave from the upper right to the lower left of the liquid film can be observed. This wave is probably due to the slot in the injection valve before injection. Since low kinematic fluid is easily affected by external force, it is considered that a velocity difference occurs inside the liquid due to the force in the swirling direction of the slot, and a spiral wave is generated.

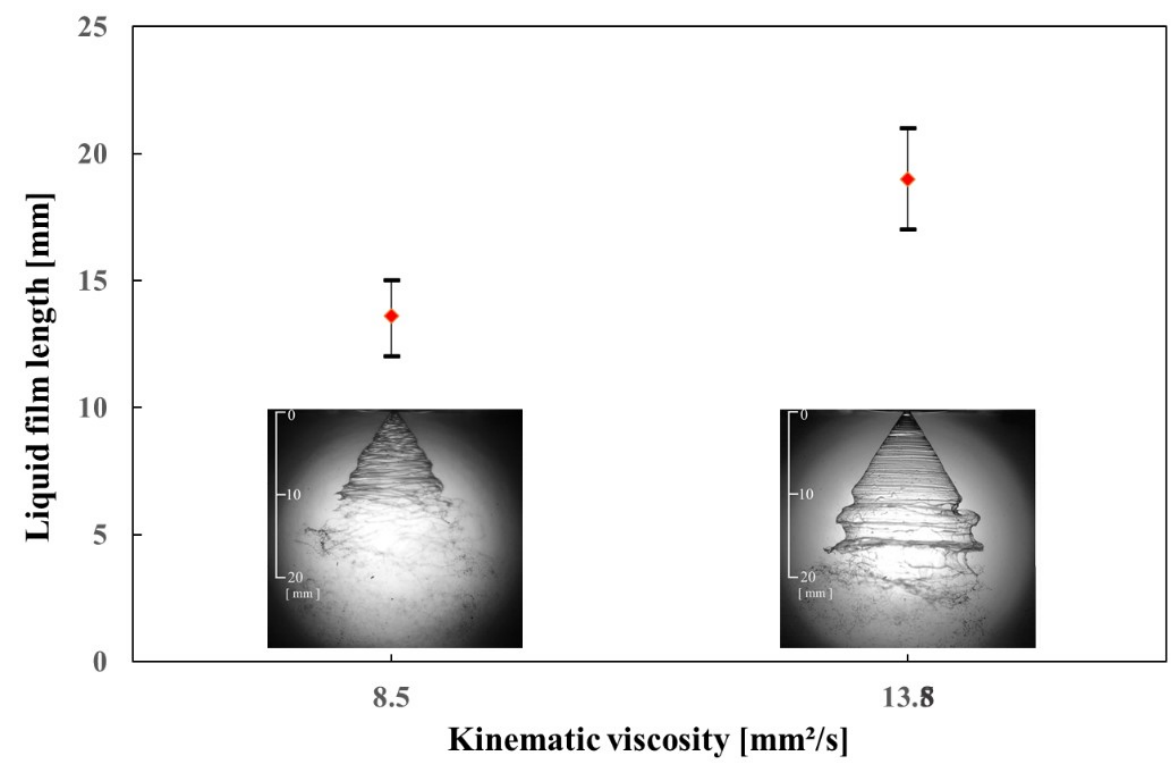

Fig.3 Difference in liquid film length for different kinematic viscosities

\subsection{Effect of swirling air flow on spray shape}

Figure 4 shows the spray shape at $v=13.8 \mathrm{~mm}^{2} / \mathrm{s}$ when the swirling air flow is not applied and when $400 \mathrm{~L} / \mathrm{min}$ is applied. When a swirling air flow is applied, the liquid film shape changes to a spindle shape. The length of the liquid film also extends in the downstream direction. Because the swirling direction given to the spray and the swirling direction of the swirling air flow are in opposition, in the downstream part of the liquid film that is easily affected by the swirling air flow, the development in the radial direction of the spray is suppressed due to the relative velocity between gas and liquid, and the shape changes to a spindle type. It is also considered that the development in the direction of the spray axis was promoted and stretched thinly. Figure 5 shows the spray shape when swirling air flow is not applied and when $400 \mathrm{~L} / \mathrm{min}$ is applied at $v=8.5 \mathrm{~mm}^{2} / \mathrm{s}$. There is no significant difference in the liquid film shape and liquid film length even when a swirling air flow is applied. It is considered that this is because the liquid film breaks up before being affected by the swirling air flow while maintaining a strong inertial force at the upper part of the liquid film. Figure 6 shows a trace of the outer edge of the liquid film when the swirling air flow rate is changed at each kinematic viscosity in order to investigate the liquid film behavior in time series. The trace shown in Fig. 6 was obtained from 10 consecutive spray images. When $v=13.8 \mathrm{~mm}^{2} / \mathrm{s}$, the fluctuation width of the liquid film becomes smaller due to the swirling air flow supply. In addition, there is no significant difference in the injection angle $\theta_{1}$ near the injection port at this time. Similarly, 
when $v=8.5 \mathrm{~mm}^{2} / \mathrm{s}$, the fluctuation width of the liquid film becomes smaller by applying a swirling air flow. In addition, there is no significant difference in the injection angle $\theta_{2}$ near the injection port. The waviness of the liquid film surface in Fig. 6 can be confirmed under any conditions regardless of the presence or absence of swirling air flow, and it is considered that the influence of Kelvin-Helmholtz Instability (KHI) caused by the speed difference between the ambient air and the liquid film is dominant. Considering the KHI, the instability and the fluctuation width of the liquid film became smaller because the gas-liquid velocity difference decreased due to the swirling air flow supply.

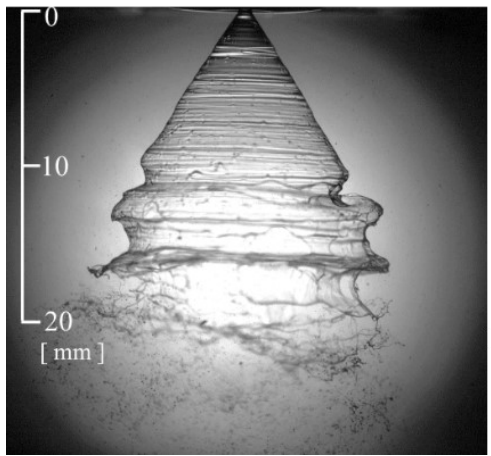

(a) $Q=0 \mathrm{~L} / \mathrm{min}$

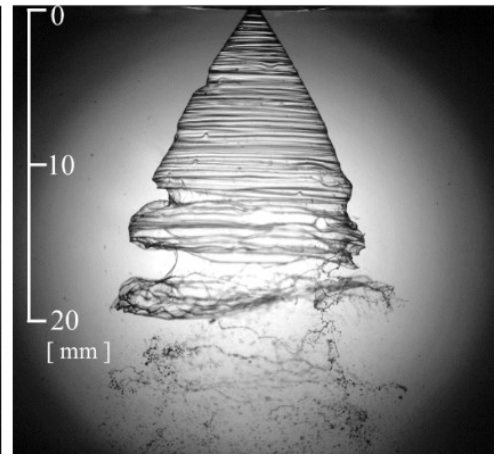

(b) $Q=400 \mathrm{~L} / \mathrm{min}$

Fig.4 Typical images of spray shape for different swirling air flow rates $\left[v=13.8 \mathrm{~mm}^{2} / \mathrm{s}\right]$

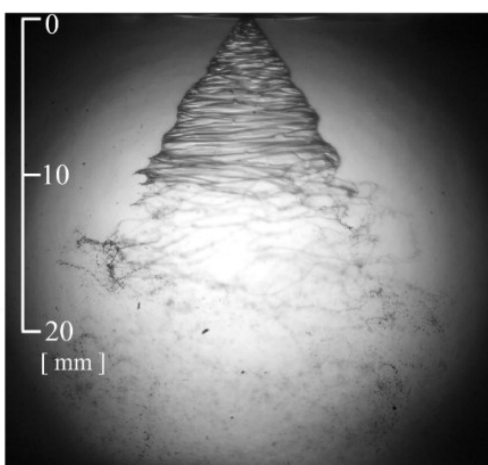

(a) $Q=0 \mathrm{~L} / \mathrm{min}$

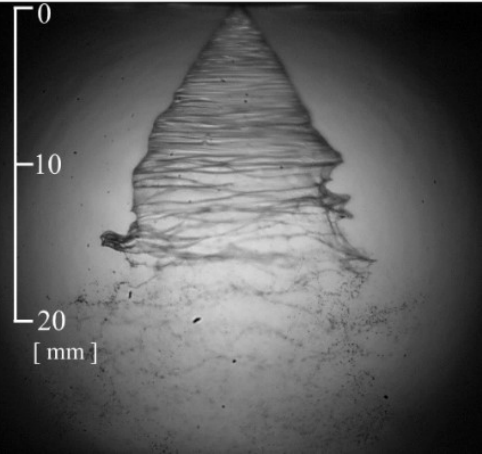

(b) $Q=400 \mathrm{~L} / \mathrm{min}$

Fig.5 Typical images of spray shape for different swirling air flow rates $\left[v=8.5 \mathrm{~mm}^{2} / \mathrm{s}\right]$

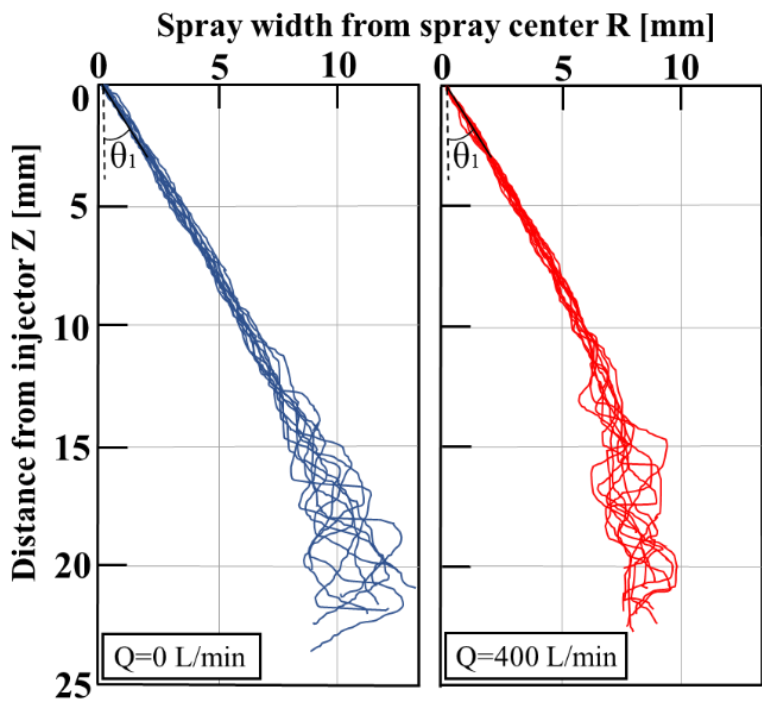

(a) $v=13.8 \mathrm{~mm}^{2} / \mathrm{s}$

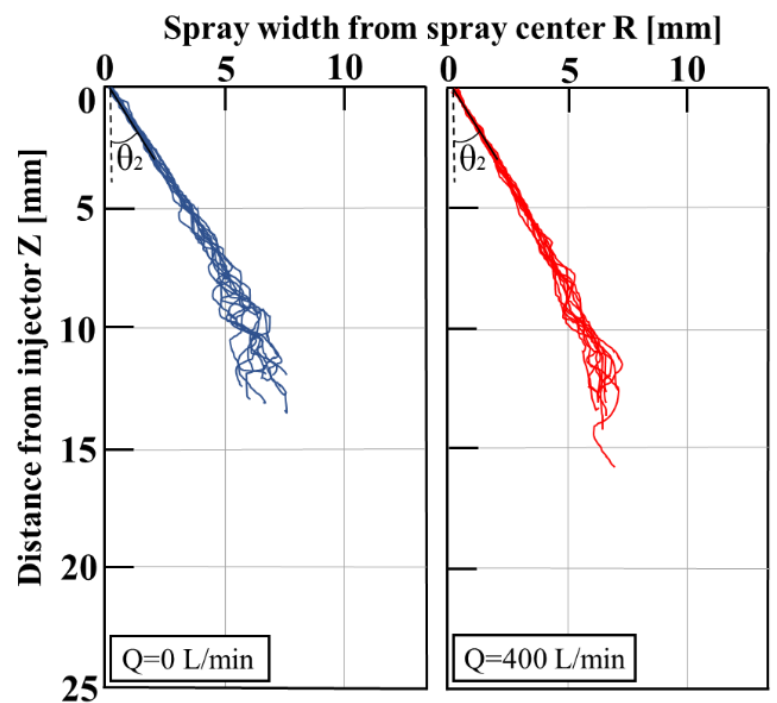

(b) $v=8.5 \mathrm{~mm}^{2} / \mathrm{s}$

Fig.6 Liquid film behavior for different kinematic viscosities 


\subsection{Droplet size distribution}

Figure 7 shows the droplet size distribution of droplets measured per unit time using PDPA under both conditions of swirling air flow $Q=0 \mathrm{~L} / \mathrm{min}$ and $500 \mathrm{~L} / \mathrm{min}$. Under the condition of $Q=0 \mathrm{~L} / \mathrm{min}$, the droplet size distribution at $X=0,3 \mathrm{~mm}$ has a peak around $25 \mu \mathrm{m}$, and at $X$ $=6,9 \mathrm{~mm}$, the number of droplets increases and the peak is around $15 \mu \mathrm{m}$. It moved to the microdroplet side. It was confirmed that the number of droplets decreased and the peak increased to $40 \mu \mathrm{m}$ at $X=12$ and $15 \mathrm{~mm}$. Under the condition of $Q=500 \mathrm{~L} / \mathrm{min}$, the droplet size distribution at $X=0$ and $3 \mathrm{~mm}$ is almost unchanged, and the droplets near the spray center are not affected by the swirling air flow at $Z=35 \mathrm{~mm}$. At $X=6,9 \mathrm{~mm}$, the peak was around $30 \mu \mathrm{m}$. As compared with the result at the same position of $Q=0 \mathrm{~L} / \mathrm{min}$, the number of droplets decreased overall, and the number of droplets with a diameter of $30 \mu \mathrm{m}$ or less decreased significantly. At $X=12$ and $15 \mathrm{~mm}$, the tendency of the peak droplet diameter and droplet size distribution is almost the same as the result of $X=6$ and $9 \mathrm{~mm}$, but the number of droplets is increasing. There is also an increase compared to the result at the same position with $\mathrm{Q}=0 \mathrm{~L} / \mathrm{min}$.

From the above, it was found that applying a swirling air flow affects the number of droplets, the droplet size distribution of the droplets, and the movement of the spray.
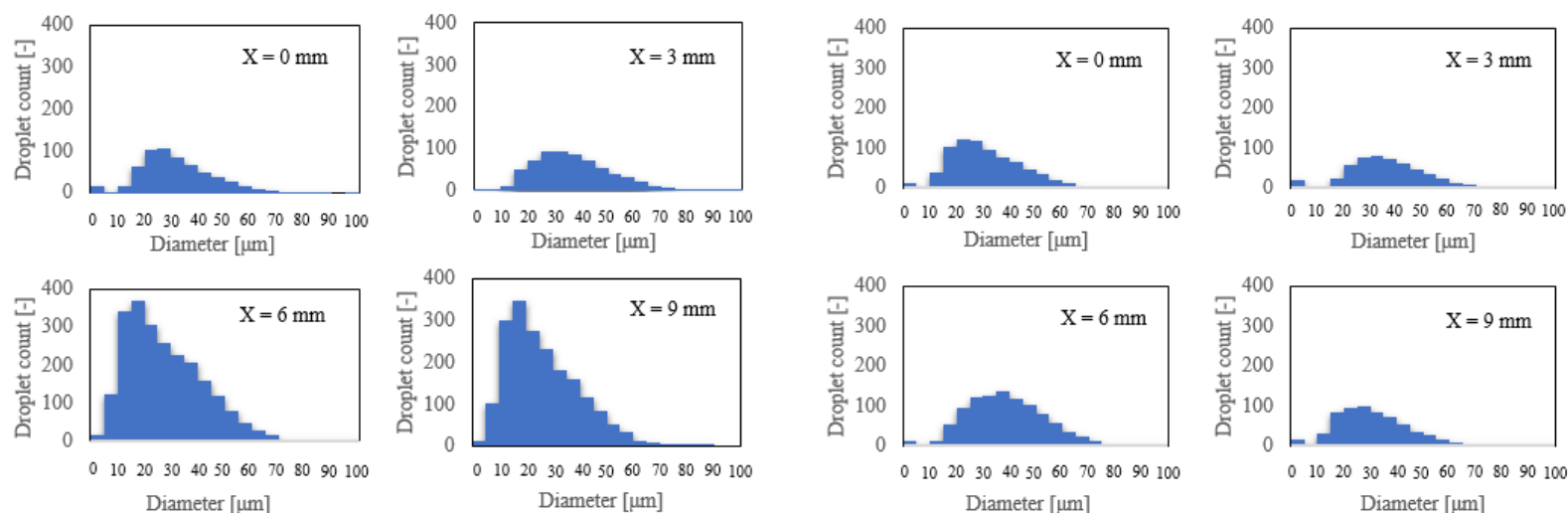

Diameter $[\mu \mathrm{m}]$

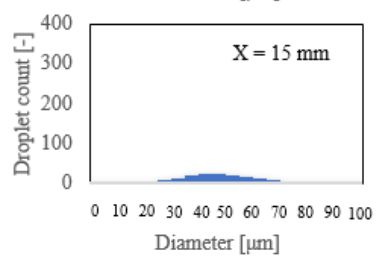

(a) $Q=0 \mathrm{~L} / \mathrm{min}$
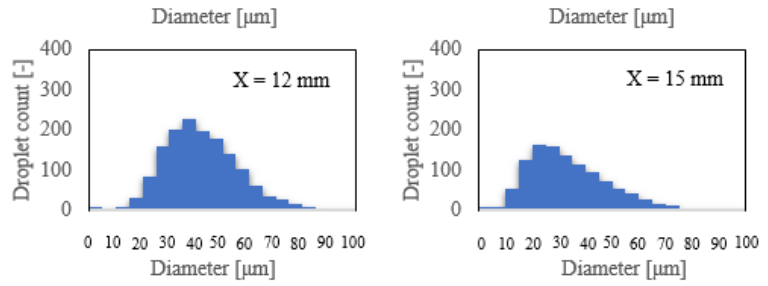

(b) $Q=500 \mathrm{~L} / \mathrm{min}$

Fig.7 Droplet size distribution for different positions ( $X=0 \sim 15 \mathrm{~mm}, \quad Z=35 \mathrm{~mm}$ ) 


\section{CONCLUSION}

In this experiment, we investigated how the spray shape of the liquid is affected by applying a swirling air flow in a low pressure atmosphere that simulates the high-altitude condition using a jet fuel simulated liquid. We also investigated the spray characteristics using PDPA. The findings obtained are shown below.

1. The kinematic viscosity affects the spray shape, and the higher the kinematic viscosity value, the longer the liquid film length.

2. The swirling air flow affects the spray shape, and the larger the swirling air flow rate, the longer the liquid film becomes and the liquid film shape changes to a spindle shape. In addition, the fluctuation range of the liquid film becomes smaller.

3. By applying a swirling air flow, the peak of the particle size distribution is around $30 \mu \mathrm{m}$ and shows a relatively same particle size distribution at any point. In addition, the number of droplets with a diameter of $30 \mu \mathrm{m}$ or less decreases, and the number of droplets increases toward the circumference.

\section{REFERENCES}

[1] Japan Aircraft Development Corporation, Worldwide Market Forecast 2020-2039 Report, p. 85, (2020)

[2] Neya, K. and Sato, S., Effect of Ambient Air Pressure on the Spray Characteristics of Swirl Atomizers, JSME International Journal Series B-fluids and Thermal Engineering, pp. 817-826, (1967)

[3] Fraser, R. P., Eisenklam, P., Dombrowski, N., and Hasson. D., Drop Formation from Rapidly Moving Liquid Sheets, A.I.Ch.E. Journal, Vol. 8, No. 5, (1967)

[4] Choi, C., Lim, B., and Choi, S., : Spray Characteristics of the Pressure Swirl Injector in the Annular Reverse Combustor, ILASS-ASIA-2008, pp. 45-48, (2008)

[5] Lefebvre, A. H., Atomization and Sprays, Taylor \& Francis, (1989)

[6] Kanda, T., A Study of Breakup Process of a Jet Fuel Simulant Liquid at Low Pressure, Yamaguchi University Master's Thesis in japanese, p. 16, (2015) 